\title{
Joint Interpretation of Magnetotelluric and Seismic Models for Exploration of the Gross Schoenebeck Geothermal Site
}

\author{
G. Muñoz, K. Bauer, I. Moeck, O. Ritter \\ GFZ Deutsches GeoForschungsZentrum
}

\section{Introduction}

Due to the non-uniqueness of the inverse problem, the interpretation of geophysical models in terms of geological units is not always straightforward. It is common to use a combination of different geophysical methods to obtain the distribution of independent physical properties over the area of interest in order to discriminate between the different lithologies or geologic units. This kind of studies is usually limited to qualitative comparisons of the different models, which may - or may not -support a relation between the parameters in certain areas. Quantitative approaches are in general based on empirical relations between physical parameters, which often are not of universal applicability.

The magnetotelluric (MT) and seismic methods resolve the physical parameters electric resistivity $(\rho)$ and (seismic) velocity $\left(V_{p}, V_{s}\right)$ respectively with similar spatial resolution and are often used in combination to derive earth models. By looking at both resistivity and velocity simultaneously, we can keep the strengths of both methods while avoiding their weaknesses. The problem with a joint interpretation is that there is no unique universal law linking electrical and acoustic properties. While electrical resistivity in deep sedimentary basins is mostly sensitive to the pore geometry and contents, seismic velocity is mostly imaging rock matrix properties. However, with a statistical analysis of the distributions of both resistivity and velocity, we can find certain areas of the models space where a particular relation between the physical parameters holds locally, thus allowing us to characterize this region as a particular lithology. In the present work, we use a statistical analysis, as described by Bedrosian et al. (2007) in order to correlate two independently obtained models of the Groß Schönebeck geothermal test site in the Northeast German Basin.

\section{Methodology description}

The methodology used in the present paper was described by Bedrosian et al. (2007) and is based on a probabilistic approach developed by Bosch (1999), in a sense that diverse geophysical parameters are represented as a probability density function (pdf) in the joint parameter space. The coincident velocity and resistivity models are first interpolated onto a common grid. Therefore, a joint parameter space is built, where each point in the modelled area is associated with a velocity - resistivity pair. By plotting one parameter against the other in a cross-plot and including the error estimates we can then construct a joint pdf in the parameter space. The areas of enhanced probability can be identified with classes represented by a certain range of values in both resistivity and velocity. By mapping back these classes onto the spatial domain they can be related to certain lithologies and/or geological units.

In the present work, the resistivity model was interpolated onto the seismic mesh, given that it is uniformly spaced and finer than the magnetotelluric mesh. An inverse distance weighted interpolation scheme was used, which forms estimates from a weighted average of many samples found within a pre-defined area around the point, with decreasing weights with distance.

Each element of this distribution can be interpreted as the outcome of a process defined by a probability density function (pdf). Assuming normal error distribution and independence of the data, the joint $p d f$ is expressed as the sum of the individual pdfs $\left(p d f_{i}\right)$ for each data point, 
according to the following expression, with the errors of the resistivity and velocity $\left(\delta \log \left(\rho_{\mathrm{i}}\right)\right.$ and $\delta \mathrm{V}_{\mathrm{p}, \mathrm{i}}$ ) estimated from the sensitivity matrix and the hit count distribution respectively:

$$
\begin{gathered}
p d f\left(\rho, v_{p}\right)=\frac{1}{n} \sum_{i=1}^{n} p d f_{i}\left(\rho, v_{p}\right) \\
p d f_{i}\left(\rho, v_{p}\right)=\frac{1}{\sqrt{2 \pi \delta \log \left(\rho_{i)} \delta V_{p, i}\right.}} \times \exp -\frac{1}{2}\left[\frac{\left(\log (\rho)-\log \left(\rho_{i}\right)\right)^{2}}{\delta \log \left(\rho_{i}\right)^{2}}+\frac{\left(V_{p}-V_{p, i}\right)^{2}}{\delta V_{p, i}^{2}}\right]
\end{gathered}
$$

The different classes are identified as zones of enhanced probability in the joint pdf crossplot. Assuming that the geological units are characterized by uniform physical properties normally distributed, each class is defined by a mean point and a covariance matrix (representing the $\sim 60$ per cent confidence interval ellipse for the peak) in the joint parameter space.

\section{Geophysical models}

The Groß Schönebeck low enthalpy geothermal site, with the well doublet GrSk 3/90 and GrSk 4/05, is located in the Northeast German Basin (NEGB). MT data was collected along a $40 \mathrm{~km}$-long profile centred on the well doublet. The profile consists of 55 stations with a site spacing of $400 \mathrm{~m}$ in the central part (close to the borehole) of the profile, increasing to $800 \mathrm{~m}$ towards both profile ends. The period range of the observations was 0,001 to $1000 \mathrm{~s}$. This profile is spatially coincident with the seismic tomography profile and most of the stations were located at the same places as the seismic shot points. At all sites, we recorded horizontal electric and magnetic field components and the vertical magnetic field.

The resistivity model for the MT profile (Figure 1a) shows a shallow conductive layer extending from the surface down to depths of about $4 \mathrm{~km}$, with an antiform-type shape below the central part of the profile. At a depth range of $4-5 \mathrm{~km}$ two conductive bodies are found, separated by a region of moderate conductivity. According to the seismic tomography, which shows high velocity values for depths greater than $4 \mathrm{~km}$, a resistive basement was introduced a priori in the resistivity model (Muñoz et al., 2010).

A $40 \mathrm{~km}$ long seismic profile was measured coincident with the MT experiment (Figure 1b). The objective was to derive a regional 2-D seismic model, which can be combined with the electrical conductivity model from the MT data analysis to study the potential reservoir layers and overlying sediments. The experimental setup was designed to provide data suitable for refraction tomography. 45 explosion shots were fired from $20 \mathrm{~m}$ deep boreholes with charge sizes of $30 \mathrm{~kg}$. The shot spacing was $800 \mathrm{~m}$ on average. The recording instrumentation consisted of $4.5 \mathrm{~Hz} 3$-component geophones. These were deployed as a $40 \mathrm{~km}$ long receiver spread with spacings of $200 \mathrm{~m}$. Each shot was recorded by all receivers.

The velocity model (Figure 1b) can be divided into three major sequences: The upper section (depth range $0-2 \mathrm{~km})$ is characterized by low velocities $(2-3.5 \mathrm{~km} / \mathrm{s})$ and a strong increase of velocity with depth. The section between 2 and $4 \mathrm{~km}$ depth shows velocities between 4 and $4.5 \mathrm{~km} / \mathrm{s}$ and is characterized by a strong topography on top which is related with salt mobility. The third, deepest section is bounded on top by a subhorizontal interface at $4.2 \mathrm{~km}$ depth and reveals velocities of more than $5 \mathrm{~km} / \mathrm{s}$ (Bauer et al., 2010). 

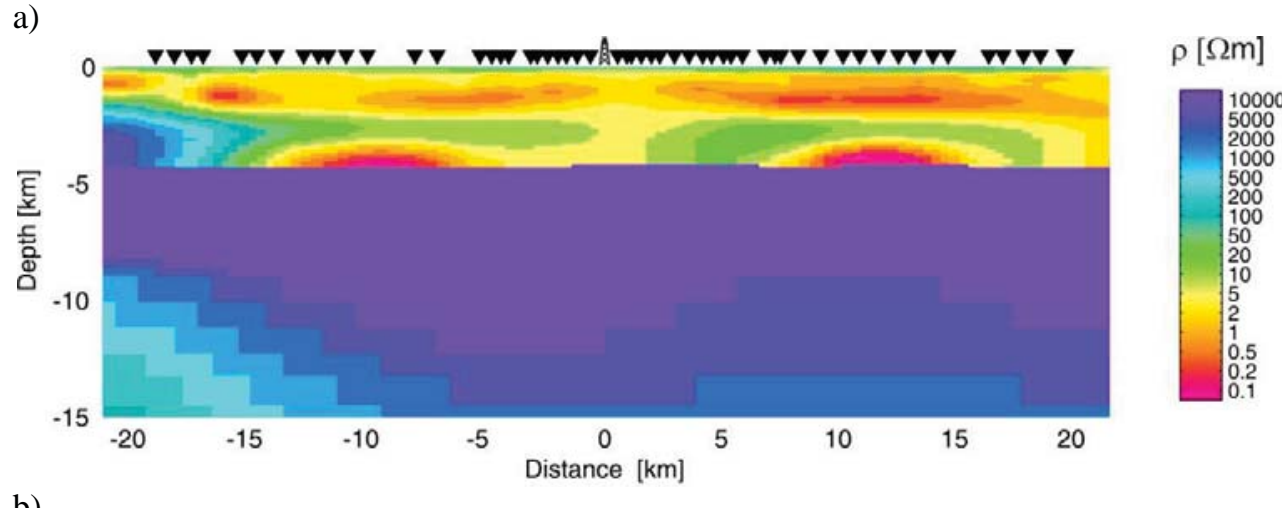

b)

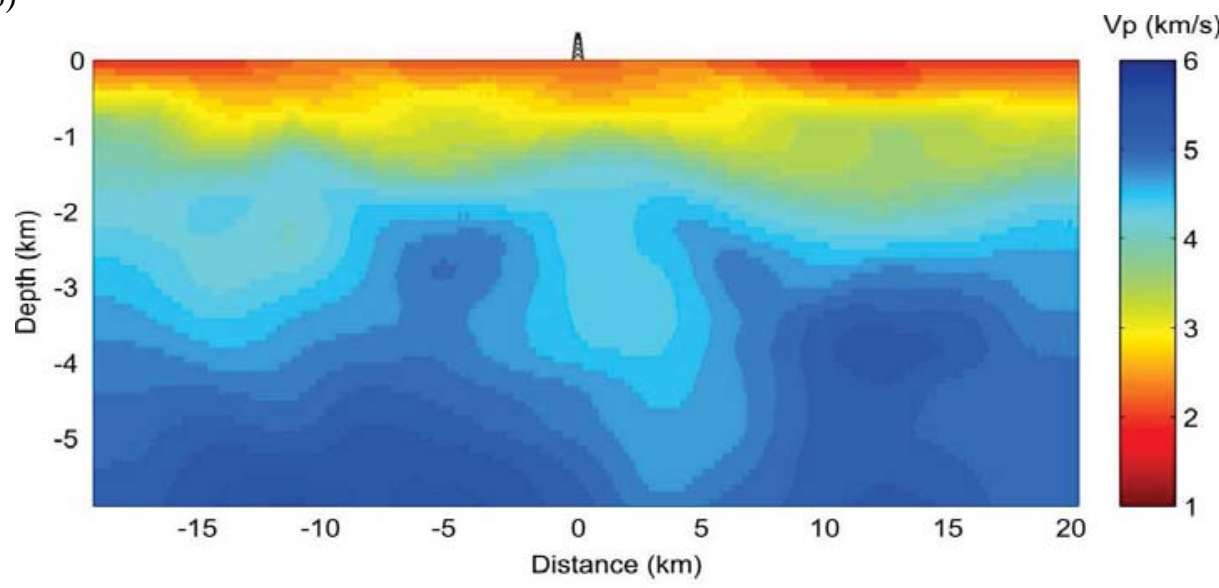

Figure 1: Electrical resistivity model obtained from inversion of the magnetotelluric data using a priori information from the seismic velocity model for the deeper part of the model (> $5 \mathrm{~km})(a)$ and seismic velocity model obtained from $\left(V_{p}\right)$ travel time inversion $(b)$.

\section{Joint analysis}

In the cross-plot of the probability density function (Figure 2a) we can identify five more or less clear peaks, or areas of enhanced probability with respect to the neighbouring region. The coloured ellipses in Figure 2a represent the $\sim 60$ per cent confidence intervals of the Gaussian peaks best fitting the pdf. The clusters were mapped back to the cross section providing a depth distribution of the classes along the profile (Fig. 2c). In order to interpret the nature of these litho-types, the model is superimposed on the stratigraphy derived from pre-existing reflection seismic data and borehole information (Moeck et al., 2008).

Class 1, the shallowest, is characterised by low velocity $(1.8-2.7 \mathrm{~km} / \mathrm{s})$ and moderate resistivity $(5-70 \Omega \mathrm{m})$ and comprises of unconsolidated sediments. Class 2 , with higher velocities $(2.7-3.9 \mathrm{~km} / \mathrm{s})$ and lower resistivities $(0.5-3.5 \Omega \mathrm{m})$ encompasses weak or soft rocks with high porosity, which are more conductive because they provide storage for a greater volumes of fluids. Class 3 coincides with successions of Middle Triassic to Lower Permian. Significantly these successions represent harder brittle rock of limestone and sandstone as indicated by increasingly higher velocities $(4-5 \mathrm{~km} / \mathrm{s})$ and resistivities $(2-15$ $\Omega \mathrm{m}$ ). This class includes also thick salt rock layers (Zechstein) which, however, yield no significant variation of resistivity or velocity within the class. Class 4 , the deepest one, is characterized by the highest velocity and resistivity values $(4.7-5.5 \mathrm{~km} / \mathrm{s}$ and around 3000 $30000 \Omega \mathrm{m}$ ). It represents the basin floor, comprising volcanic rock, quartzite and slate. This 
class reflects the fact that the magnetotelluric model used seismic a priori information to introduce a resistive basin floor. Obviously this causes the very high correlation between velocity and resistivity of class 4 in Fig. 2b. Class 5 is characterized by high velocities $(4.7-$ $5.5 \mathrm{~km} / \mathrm{s})$ but extremely low resistivities $(0.1-0.7 \Omega \mathrm{m})$.

a)

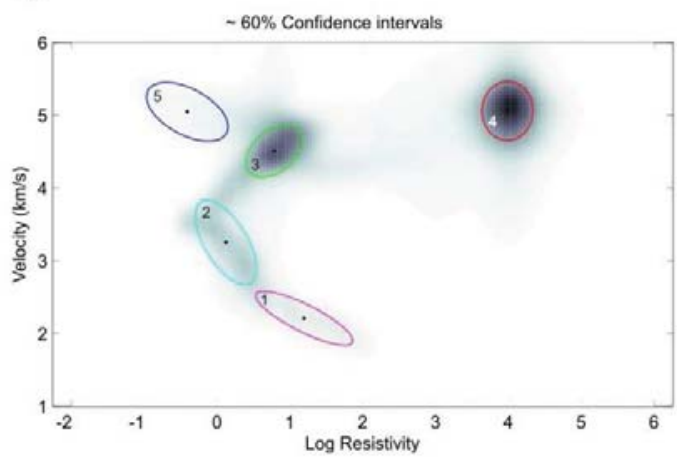

b)

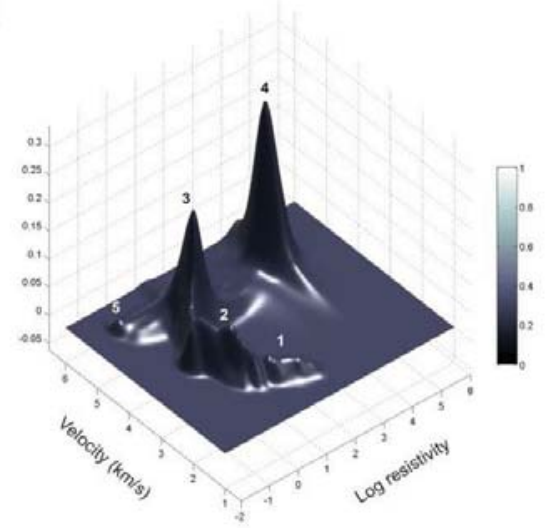

c)

Clusters in spatial domain, 5 peaks

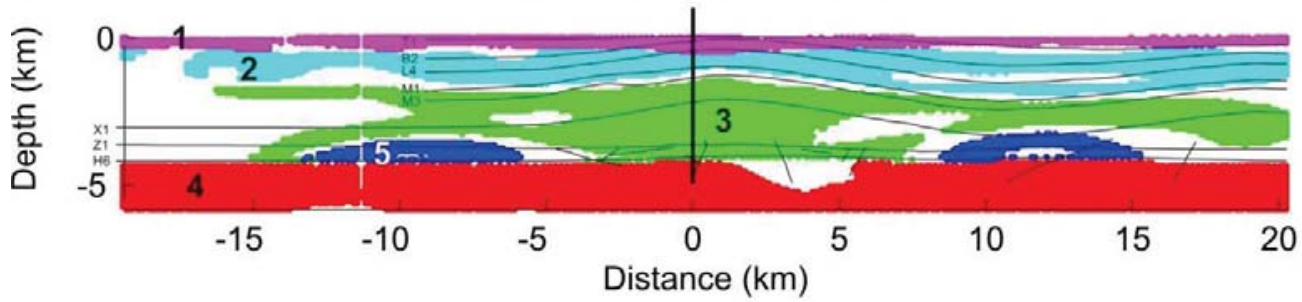

Figure 2: Cross-plot of the probability density function in gray-scale plan view (a) and threedimensional view (b). Spatial distribution of classes (c). Colours correspond with the ellipses in (a) defining the class boundaries.

It is remarkable that Class 5 is restricted to salt lows where presumably anhydrites of Upper Permian age remain after salt movement. These anhydrites have a brittle behaviour and are expected to be highly fractured. In this case, an estimation of the resistivity by using Archie's Law (Archie, 1942) for fracture-controlled porosity and assuming a formation fluid salinity of $260 \mathrm{~g} / \mathrm{l}$ (Giese et al., 2001), and a reasonable range of porosities and temperatures (15\% and $130^{\circ} \mathrm{C}$ ) the modelled resistivities of $0.1-0.7 \Omega \mathrm{m}$ can be explained. High velocities can be explained by the high density of anhydrite $\left(2.9 \mathrm{~g} / \mathrm{cm}^{3}\right)$. The classes are summarized in the Table 1, below.

\begin{tabular}{|c|c|c|c|c|}
\hline Class & $\rho(\Omega m)$ & $\mathrm{V}_{\mathrm{p}}(\mathrm{km} / \mathrm{s})$ & Lithology & Stratigraphic unit(s) \\
\hline 1 & $5-70$ & $1.8-2.7$ & $\begin{array}{l}\text { Unconsolidated sediments (sand, gravel } \\
\text { clay) }\end{array}$ & Cenozoic \\
\hline 2 & $0.5-3.5$ & $2.7-3.9$ & $\begin{array}{l}\text { Clay, marl, marly limestone, limestone, } \\
\text { sandstone }\end{array}$ & Cretaceous - Upper Triassic \\
\hline 3 & $2-15$ & $4-5$ & $\begin{array}{l}\text { Brittle limestone, sandstone, } \\
\text { evaporites }\end{array}$ & $\begin{array}{l}\text { Middle Triassic-Lower } \\
\text { Permian }\end{array}$ \\
\hline 4 & $3 \cdot 10^{3}-3 \cdot 10^{4}$ & $4.7-5.5$ & Volcanic rock, quartzite, slate & $\begin{array}{l}\text { Lower Permian - } \\
\text { Carboniferous }\end{array}$ \\
\hline 5 & $0.1-0.7$ & $4.7-5.5$ & Anhydrite & Lower Permian \\
\hline
\end{tabular}

Table 1: Resistivity and P velocity of the classes from figure 9. Also included are lithology and stratigraphic units. 


\section{Conclusions}

MT and seismic data were used to derive independent 2-D models of the electrical conductivity and the seismic P velocity around the geothermal research well GrSk 3/90. The resulting models were combined in a statistical analysis to determine correlating features in both models. The classification method used in this analysis revealed 5 distinct litho-types which show up as separate clusters in the underlying geophysical parameter space of $\mathrm{Pa}$ and VP.

This study demonstrates the concert of MT, seismic and structural geologic models. Therefore the combination of different geophysical methods (MT and seismic) combined with structural geological information revealed information which was previously unknown and which could not be determined with the individual methods. Clearly, this approach is applicable in other areas too and could represent a promising new approach for geothermal exploration.

\section{Acknowledgements}

This work was funded within the $6^{\text {th }}$ Framework Program of the European Union (I-GET Project, Contract $n^{\circ}$ 518378). The instruments for the geophysical experiments were provided by the Geophysical Instrument Pool Potsdam (GIPP). We wish to thank Paul Bedrosian for making his statistical analysis code available to us.

\section{References}

Archie, G. [1942] The electrical resistivity $\log$ as an aid in determining some reservoir characteristics. Trans. Am. Inst. Min. Metall. Pet. Eng., 146, 54-62.

Bauer, K., Moeck, I., Norden, B., Schulze, A., Weber, M. [2010] . Tomographic P velocity and gradient structure across the geothermal site Gross Schoenebeck (NE German Basin): Relationship to lithology, salt tectonics, and thermal regime. J. Geophys. Res., Submitted.

Bedrosian, P.A., Maercklin, N., Weckmann, U., Bartov, Y., Ryberg, T., Ritter, O. [2007] Lithology-derived structure classification from the joint interpretation of magnetotelluric and seismic models. Geophysical Journal International, 170, 737-748.

Bosch, M. [1999] Lithologic tomography: from plural geophysical data to lithology estimation. Journal of Geophysical Research, 104, 749-766.

Giese, L., Seibt A., Wiersberg T., Zimmer M., Erzinger J., Niedermann S. and Pekdeger A. [2001] Geochemistry of the formation fluids, in: 7. Report der Geothermie Projekte, In situGeothermielabor Groß Schönebeck 2000/2001 Bohrarbeiten, Bohrlochmessungen, Hydraulik, Formationsfluide, Tonminerale. GeoForschunsZentrum Potsdam.

Moeck, I., Schandelmeier, H., Holl, H.G. [2008] The stress regime in Rotliegend reservoir reservoir of the Northeast German Basin. International Journal of Earth Sciences (Geol. Rundsch.), doi:10.1007/s00531-008-0316-1.

Muñoz. G., Ritter, O., Moeck, I. [2010] A target-oriented magnetotelluric inversion scheme for characterizing the low enthalpy Groß Schönebeck geothermal reservoir. Geophysical Journal International, submitted. 